\title{
Chapter 10 \\ Increasing Inequality and the Changing Spatial Distribution of Income in Tel-Aviv
}

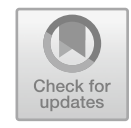

\author{
Tal Modai-Snir
}

\begin{abstract}
Despite its egalitarian past, in recent decades Israel followed the footsteps of the United States in terms of growing inequality levels and reduced welfare arrangements. It is assumed, therefore, to have followed similar trends of increasing residential segregation between income groups. This study focuses on the metropolitan area of Tel-Aviv, Israel's financial and cultural centre and examines the change in the spatial distribution of income groups between the years 1995-2008. It identifies trends in segregation between top and bottom income earners, as well as those between other income groups, given corresponding trends in income inequality. In addition, it examines spatial patterns of affluence and poverty concentration and assesses the influence of concentrated disadvantage among specific income and religious groups on overall segregation trends.
\end{abstract}

Keywords Spatial inequality $\cdot$ Income segregation $\cdot$ Tel-aviv $\cdot$ Inequality trends

\subsection{Introduction}

The level of residential segregation by income (income segregation from hereafter) is affected by the level of income inequality. This association has been investigated in several studies during the past decade (Watson 2009; Reardon and Bischoff 2011; Tammaru et al. 2015, 2019; Quillian and Lagrange 2016), and there is growing insight about several aspects of this relationship. First, it is understood that different characteristics of the income distribution affect the segregation of different income strata. Second, it is known that the residential distribution of income groups can follow diverse spatial patterns. Finally, it is acknowledged that given income disparities among ethnic or social sub-groups, increasing inequality affects the segregation between such groups.

This chapter focuses on the metropolitan area of Tel-Aviv, Israel's financial and cultural centre. It examines the change in income segregation between the years 1995

\author{
T. Modai-Snir $(\bowtie)$ \\ Delft University of Technology, Delft, Netherlands \\ e-mail: talmodai@yahoo.com
}


and 2008. Those were the years when population censuses were conducted, but also a period in which inequality substantially increased. The study follows segregation trends of various income-group combinations, relating them to trends in inequality at different parts of the income distribution. A popular belief in Israel attributes a large extent of inequality to the effect of two extremely disadvantaged groups in society, Arabs and ultra-orthodox Jews. This study, therefore, also examines the effects of those groups on total income segregation in the metropolitan area.

The objective of this chapter is to explore patterns of change in the spatial distribution of income classes in the Tel-Aviv metropolitan area. The chapter will address several questions that arise given the background of Israel's inequality trends, its unique socio-demographic context and the patterns of urban development in the TelAviv MA: How did the segregation of different income classes evolve and how did segregation patterns correspond to inequality trends? Did the increasing relative disadvantage of Arabs and ultra-orthodox Jews play a role in increasing income segregation? How are the different income classes spatially distributed? Is this distribution indicative of spatial patterns of poverty/affluence concentration?

\subsection{Increasing Income Inequality in Israel and Socio-spatial Implications}

Israel was born as a socialist state in 1948 and through its first decades was characterized by a progressive welfare policy. The days of socialism came to an end within three decades. A political upheaval in 1977 marked a shift to a neo-liberal regime, when the labour party, which led all governments until then, handed over the reins to a right-wing coalition. This political shift is believed to have transformed Israeli society. Another event, however, has also been considered a turning point in Israel's economy. A dramatic stabilization programme, which was conceived in 1985 following a severe economic crisis, reflected a final transition from socialism to capitalism.

Following these developments, and as part of Israel's integration in the global economy, income inequality levels have increased substantially since the $1980 \mathrm{~s}$. The Gini coefficient for disposable incomes ${ }^{1}$ increased from 0.33 in 1985 to 0.38 in 2010. Inequality in market incomes also increased substantially due to structural processes in the labour market, with Gini coefficients mounting from a low of 0.47 in 1985 to a high 0.51 in 2005 . The significant reductions in direct taxes and transfers resulted in increased participation in the labour market and decreased unemployment, which led to a substantial decrease in inequality, based on market incomes, from 2005 onwards. Inequality in disposable incomes, however, remained very high given the reduced transfers (Cornfeld and Danieli 2015), and as of 2015, Israel stands out together with the US as the most unequal among developed countries (OECD 2015).

\footnotetext{
${ }^{1}$ OECD data, extracted from OECD.Stat.
} 
Israel also stood out (as of 2005) as having extreme upper and lower tail inequality (Ben-David and Bleikh 2013). Trends in wage decile ratios over the past decades indicate substantial increases in upper tail inequality (P90/P50) and decreases in lower tail inequality (P50/P10) during about a decade since the mid 1990s, which offset increases in that inequality during the previous decade (Cornfeld and Danieli 2015). The concentration of income among the top decile and top percentile is less extreme in Israel than in several OECD countries (Ben-David and Bleich 2013, as of 2005).

Increasing residential segregation appears from increasing income disparities among classes that affect the differential spending on housing. The increase in inequality levels involves diverse changes in the distribution of income and correspondingly, there may be diverse patterns of change in income segregation. Under conditions of increasing inequality, income disparities between the top and bottom classes inevitably increase and so does the segregation of top and bottom income groups. A study of income inequality and segregation among 13 European cities revealed that, in all of them, segregation between top and bottom classes increased with the increase in income inequality (Marcińczak et al. 2015). Increasing inequality may also manifest in changing disparities within different parts of the distribution which can affect income segregation, respectively. Lesser disparities in the lower part of the distribution and greater disparities in the upper part of the distribution are associated with greater segregation of affluence which is a most common aspect of segregation in contemporary cities of the developed world (Reardon and Bischoff 2011; Marcińczak et al. 2015; Quillian and Lagrange 2016).

The degree to which the income differential is translated into increasing residential segregation depends, to a great extent, on housing policies. The decline of the Israeli welfare state manifested also in the evolution of housing policies. During the first decades after Israel's establishment, housing policies were directed to achieve collective goals such as immigrant absorption and population dispersal in the country's periphery (Carmon 2001). The public housing sector peaked at a share of around $23 \%$ by the end of the 1950 s, a share that remained stable for another decade (Werczberger and Reshef 1993). In contrast with many countries where the privatization of public housing reflected a reversal of housing policies, in Israel privatization was an ongoing policy long before the political shift, reflecting a preferential status of homeownership (Werczberger and Reshef 1993; Werczberger 1995). Privatization through the sale of public housing units to occupying renters intensified over the years and by 2015, the public housing sector constituted only $3 \%$ of the housing stock in Israel (Hananel et al. 2018). Despite the important decline of this sector, it is not assumed to have had an important role in changing residential segregation within the Tel-Aviv MA, as most public housing were located in peripheral areas. However, it may have played a role in the positioning of Israel's central urban area as increasingly wealthier. 


\subsection{Inequality Among Socio-demographic Groups in Israel}

In many cities, income disparities among ethnic groups generate complex patterns of segregation that involve both the socioeconomic dimension and the ethnic dimension. The effect of increasing income inequality on the segregation of disadvantaged social groups depends on whether disparities are growing between or within sub-groups. In addition, there is also a question of whether groups compete in the same housing submarkets. The less the groups are constrained to separate sub-markets, the stronger the link between income inequality and segregation within each sub-market (Reardon and Bischoff 2011).

The Israeli population is very heterogeneous in terms of ethnic origin and religious identity. Income inequalities are related, to some extent, to disparities among population sub-groups. The two most disadvantaged groups are $\mathrm{Arabs}^{2}$ and ultra-orthodox Jews, ${ }^{3}$ which together account for approximately $30 \%$ of the total population, and are both characterized by low education levels, low participation in the labour market and high fertility rates. Poverty rates among these groups (based on disposable incomes) significantly increased during the period 1992-2011 and reached a high of 50\% and $57 \%$, respectively (Ben-David and Bleikh 2013). The popular belief is that the high overall poverty rates in Israel (among the highest in OECD countries ${ }^{4}$ ) and the high inequality levels can be attributed to the effect of those disadvantaged sub-groups. A simulation of poverty rates excluding those sub-groups revealed that in such case poverty rates would not show important increases since the late 1990s and that the rate as of 2011 would be $8.5 \%$ points lower (ibid.). Similar simulations (excluding Arabs and ultra-orthodox Jews) with respect to inequality levels show a relatively modest reduction in the Gini index which would, nevertheless, still be very high compared to OECD countries (Ben-David and Bleikh 2013; Cornfeld and Danieli 2015).

Arabs and ultra-orthodox Jews are extremely segregated spatially. Of the total Arab population, at least $65 \%$ live in separate towns and villages ${ }^{5}$ (in which the population is almost $100 \%$ Arab). The rest who live in a few mixed cities are also highly segregated, mostly in separate neighbourhoods (Falah 1996). Of the ultraorthodox Jews population, it has been estimated that during the period 2002-2009 around $75 \%$ lived in cities or neighbourhoods identified as relatively homogeneous

\footnotetext{
${ }^{2}$ The Arab ethnic category composes approximately $20 \%$ of the Israeli population. It consists of Muslims, Christians, Druze and more, of which the former is the largest (82\% of total population with Arab ethnicity, according to 2008 census) and the most disadvantaged.

${ }^{3}$ Ultra-orthodox Jews accounted for approximately $10 \%$ of the population in 2008. Identifying the group of ultra-orthodox in statistics is very complex. These figures are estimated by Friedman et al. (2011).

${ }^{4}$ Around $18 \%$ in 2011 , according to OECD data, retrieved from OECD.Stat.

${ }^{5}$ Estimated by the author based on published census data from 2008.
} 
ultra-orthodox. ${ }^{6}$ Economic inequalities are not the main driver of segregation of either of these groups. The segregation of Arabs has been shaped by historical settlement patterns and by the ongoing political tension between the Arab minority and Jewish majority. The segregation of ultra-orthodox Jews is voluntary and is based on their rejection of secular western values, culture and lifestyles and as a means of limiting external influence on the community (Shilhav 1993). Even though segregation in these two cases is not driven by economic factors, the groups may contribute significantly to indices measuring economic segregation given their spatial isolation and distinct socioeconomic disadvantage. Since these groups do not compete in the same housing sub-markets as the majority group, their increasing relative disadvantage may manifest as increasing income segregation, whereas the sorting processes itself would not necessarily be highly affected by increasing income disparities.

Being an immigrant society, Israel's Jewish population is also very diverse in terms of ethnic origin. The main ethnic division is between Jews that originated from Europe and America and those that originated from countries in Africa and the Middle East. Those originated from Europe and America consistently held a higher socioeconomic status than those from Africa and the Middle East and income gaps are persistent (Haberfeld and Cohen 2007). The socioeconomic gap plays a role in the residential segregation of the two ethnic groups (Kraus and Koresh 2012). In contrast with Arab and ultra-orthodox Jews, those ethnic groups take part in the same housing market. Socioeconomic disparities are assumed to take the lead in residential sorting processes between those sub-groups, but prejudice and discrimination are not likely to be substantial in the housing market within Israel's central region compared to the context of non-Western immigrants in other developed countries and compared to the context of racial divisions in North America.

\subsection{The Tel-Aviv MA: Development and Transition}

The Tel-Aviv MA is Israel's financial and cultural centre. Its core city was established in 1909 as a Jewish suburb of the historical Arab city of Jaffa. The urban area developed along the Mediterranean seashore to the north and south. According to current delineations, the MA stretches between the 'Hefer Valley' regional council in the north (bordering the city of Netanya) and the city of Ashdod in the south (Fig. 10.1). The metropolitan area unites 30 cities and towns, and 183 rural settlements. The population of the Tel-Aviv MA increased from 2.45 million in 1995 to 3.23 million in 2008, constituting $44 \%$ of the Israeli population in both years. As of $2008,90.4 \%$ were Jewish, 5.4\% Arabs and 4.3\% 'others' (a category which commonly refers to nonArab Christians). More than $60 \%$ of Arabs live in six Arab towns/villages and the rest live in three mixed cities: Tel-Aviv, Lod and Ramla, where they constitute 4\%, 30\%

\footnotetext{
${ }^{6}$ These figures are based on estimates by Gurovich and Cohen-Kastro (2004) who used voting patterns to identify ultra-orthodox geographic concentrations in 1996 and updated estimates for the period 2002-2009 (Friedman et al. 2011).
} 
Fig. 10.1 Map of the Tel-Aviv MA (Source Tal Modai-Snir, Maarten van Ham, Neighbourhood change and spatial polarization: The roles of increasing inequality and divergent urban development, Cities, Volume 82, 2018, Pages 108-118, ISSN 0264-2751, https://doi. org/10.1016/j.cities.2018. 05.009, under a Creative Commons CC BY 4.0 license)

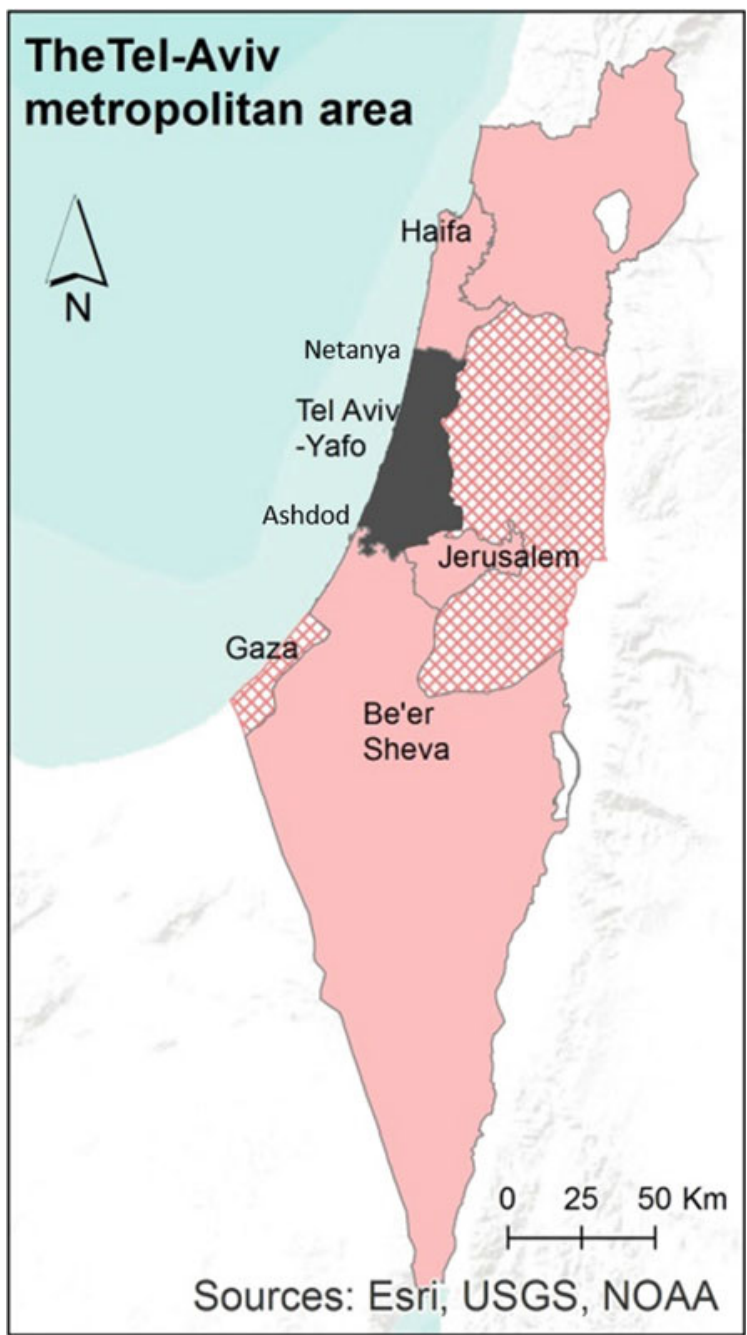

and $20 \%$ of local populations, respectively, and mostly live in predominantly Arab neighbourhoods. Of the Jewish population, approximately $8 \%$ are ultra-orthodox that live in predominantly ultra-orthodox cities and neighbourhoods.

Due to the increasing connectivity with global markets, Tel-Aviv has evolved as a world city (Kipnis 2004). While in 2000, it was classified as a Gamma city based on global connectivity rankings, ${ }^{7}$ in 2008 and 2016 it was classified Beta+ and Alpha-, respectively. These leaps in rankings exemplify the intense effect of globalization processes on the city of Tel-Aviv as well as its increasing importance worldwide. One of the claimed developments of globalizing cities is the changing income structure

\footnotetext{
${ }^{7}$ Based on The Globalisation and World Cities Research Network (https://www.lboro.ac.uk/gawc/).
} 


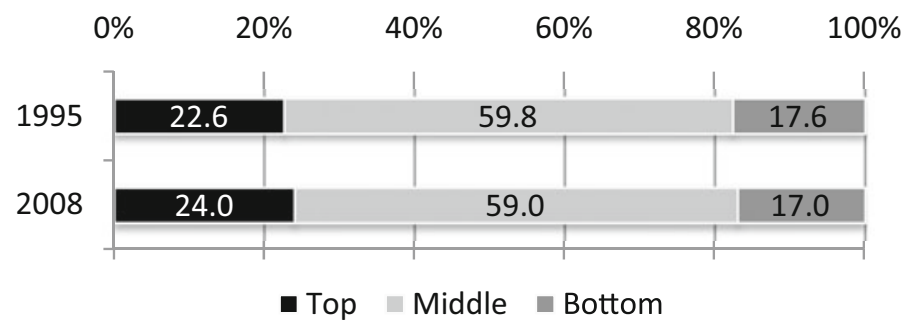

Fig. 10.2 Distribution of income groups and change over time (Processed by author based on the census data acquired specifically for this research from the Israeli CBS)

which is also evident in the Tel-Aviv MA. The top income quintile, based on the national income distribution, has gradually increased, whereas the bottom income quintile has slightly dropped (Fig. 10.2). It means that higher income groups were over-represented and lower income were under-represented in the MA. These figures indicate higher productivity and higher wages in the core region. They also most likely indicate that income sorting processes within the MA are intertwined with sorting processes occurring at the inter-regional level.

The increasing economic dominance of the MA has manifested in increasing housing demand. This led to extensive growth and expansion outwards which involved the massive conversion of agricultural land to residential use in the less urbanized periphery of the MA (Razin 1996; Bittner and Sofer 2013). This expansion reproduced the socioeconomic landscape of the historical north-south disparities that were prevalent since the establishment of Tel-Aviv city in 1909 along the historical railway to Jerusalem. The patterns of new development intensified disparities such that the MA can be considered as highly polarized between north and south (Modai-Snir and van Ham 2018).

Given the background of Israel's inequality trends, its unique socio-demographic context and the patterns of urban development in the Tel-Aviv MA, the chapter will address the following questions:

(1) How did the segregation of different income classes evolve and how did segregation patterns correspond to inequality trends? In the absence of housing policies to counteract segregation, inequality trends are expected to have translated into increased segregation of top and bottom classes. Also, the segregation of affluence is expected to increase given the increasing upper tail inequality in Israel. As the concentrations of income among the top decile are not extreme in Israel, this will manifest in the segregation of affluence which does not necessarily increase at the extreme of the income distribution.

(2) Did the increasing relative disadvantage of Arabs and ultra-orthodox Jews play a role in increasing income segregation? The modest effect of those groups on the overall inequality is expected to be replicated in the context of income segregation. Since the groups (especially Arabs) are underrepresented in the Tel-Aviv MA, the effect might turn out as negligent. 
(3) How are the different income classes spatially distributed? Is this distribution indicative of spatial patterns of poverty/affluence concentration? There is already evidence that the socio-spatial structure of the Tel-Aviv MA has developed in a spatially polarized manner. Addressing this question, additional spatial aspects of the clustering of income classes are examined, which cannot be explored using dissimilarity indices alone.

\subsection{Data and Methods}

This study is based on data from the two recent censuses, 1995 and 2008, which were processed by the Israeli Central Bureau of Statistics (CBS). Compared to other countries, therefore, census data is less updated, and the 13-year time gap between censuses is longer than the 10-year standard gap in most countries. The research area is the Tel-Aviv MA as delineated by the Israeli CBS. Its boundaries are based on functional relationships among localities that surround the city of Tel-Aviv and are identical in 1995 and 2008. The basic spatial unit used is the census tract, which is a close approximation of a neighbourhood. The division to census tracts is only available in localities with more than 10,000 residents. Smaller localities are considered one census tract.

In this study, income data was used to analyse residential segregation. The dataset comprises of counts of individuals pertaining to each income decile, of those who were employed and whose monthly income exceeded 100ILS ${ }^{8}$ including all employment statuses. Income data from the 1995 census were collected from a $20 \%$ sample. The 2008 census data were collected for the whole population from administrative sources. Income decile cut-offs are based on the national income distribution of each year, respectively. Census tracts with less than 30 employed individuals were excluded from the analysis. Also, illegal workers and asylum seekers are not included in census data, and so their effect on segregation is not accounted for. The number of census tracts, as well as the number of employees, have substantially grown between the two censuses. This reflects extensive metropolitan development during that period. The final dataset includes 900 census tracts in 1995, in which the average number of employees was 949, and 1027 census tracts in 2008, in which the average number of employees was 1484.

Income quintile counts are used for mapping location quotients and neighbourhood income compositions. Segregation is measured using dissimilarity indices for different pairs of income classes, using various aggregations of the data.

\footnotetext{
${ }^{8}$ ILS-Israeli new shekel. 100 ILS was equivalent to 20 EUR in 2008 (around 25 Euros as of 2019).
} 


\subsection{The Segregation Between Income Classes in the Tel-Aviv MA}

Dissimilarity indices (DI) for different combinations of income groups for the years 1995 and 2008 (Table 10.1) reveal the trends in income segregation. The most dominant trend is the increase in the segregation of the top group (deciles 1 and 2) from middle and middle-high groups, increases of more than $20 \%$. There were also more moderate increases in DI concerning the bottom and middle/top deciles. Those trends are also evident when focusing on aggregate income groups; the DI of the top and middle groups increased by $18 \%$, while those of top/bottom and middle/bottom groups increased by only $12 \%$ and $10 \%$, respectively. Another interesting finding is that, in 2008, the DI of the top and middle groups is not much lower than the index computed for the top and bottom groups ( 0.26 vs. 0.28 , respectively).

The level of aggregation is an important issue to consider. The segregation of top and bottom income groups appears to have increased the most when operationalized as the top and bottom quintiles (from 0.28 to $0.33,18 \%$, compared to $15 \%$ when operationalized as the top and bottom deciles and $12 \%$ when operationalized as three top and three bottom deciles). It appears that in the case of the Tel-Aviv MA, the top quintile is the most important aggregation to focus on when dealing with the segregation of affluence. The trends in income segregation, as shown in the changes in DI among income groups, conform to the evolution of inequality in Israel which has been characterized by increasing income gaps at the top of the distribution, with less extreme concentration of income at the top decile and top percentile compared to several OECD countries.

Another feature of Israel's inequality is the contribution of two disadvantaged groups, namely Arabs and ultra-orthodox Jews, to the level of inequality in Israel.

Table 10.1 Dissimilarity indices (multiplied by 100) for income groups in Tel-Aviv, 1995 and 2008 (below and above the diagonal, respectively). Top and Bottom groups refer to deciles 1-3 and 8-10, respectively, and Middle group refers to deciles 4-7. (Processed by author based on the census data acquired specifically for this research from the Israeli CBS)

\begin{tabular}{|c|c|c|c|c|c|c|c|c|c|c|c|c|c|}
\hline & 1 & 2 & 3 & 4 & 5 & 6 & 7 & 8 & 9 & 10 & TOP & MID & BOT \\
\hline 1 & & 22 & 30 & 36 & 41 & 42 & 44 & 43 & 42 & 39 & & & \\
\hline 2 & 20 & & 16 & 21 & 26 & 28 & 30 & 30 & 29 & 27 & & & \\
\hline 3 & 25 & 13 & & 15 & 18 & 20 & 23 & 22 & 22 & 22 & & & \\
\hline 4 & 30 & 18 & 14 & & 14 & 16 & 18 & 18 & 19 & 19 & & & \\
\hline 5 & 34 & 21 & 16 & 13 & & 14 & 15 & 16 & 16 & 17 & & & \\
\hline 6 & 36 & 24 & 18 & 15 & 13 & & 14 & 15 & 16 & 18 & & & \\
\hline 7 & 38 & 26 & 21 & 16 & 14 & 13 & & 15 & 15 & 17 & & & \\
\hline 8 & 39 & 27 & 21 & 17 & 15 & 13 & 14 & & 14 & 17 & & & \\
\hline 9 & 38 & 27 & 21 & 17 & 16 & 13 & 14 & 13 & & 15 & & & \\
\hline 10 & 34 & 23 & 18 & 16 & 16 & 15 & 16 & 15 & 15 & & & & \\
\hline TOP & & & & & & & & & & & & 26 & 28 \\
\hline MID & & & & & & & & & & & 22 & & 11 \\
\hline BOT & & & & & & & & & & & 25 & 10 & \\
\hline
\end{tabular}


Table 10.2 Dissimilarity indices computed for top and bottom income groups (three different classifications) in the Tel-Aviv MA, 1995 and 2008, after excluding tracts which are predominantly Arab or ultra-orthodox (Processed by author based on the census data acquired specifically for this research from the Israeli CBS)

\begin{tabular}{l|l|l|l}
\hline & 1995 & 2008 & $\%$ change (\%) \\
\hline Top/botom decile & 0.33 & 0.38 & 15 \\
\hline Top/botom 2 deciles & 0.28 & 0.32 & 14 \\
\hline Top/botom 3 deciles & 0.24 & 0.27 & 13 \\
\hline
\end{tabular}

Table 10.2 presents a simulation that aims to examine whether income segregation levels in the Tel-Aviv MA are affected by the presence of these populations. DI of top and bottom income groups, using different aggregations were computed after excluding tracts which are predominantly Arab or ultra-orthodox. In the case of the Arab minority, tracts in ethnically mixed cities were excluded if the minority accounted for more than $60 \%$ of the local population. In total, 49 tracts out of 900 were excluded in 1995 and 60 tracts out of 1027 in 2008. Excluded ultra-orthodox tracts were those identified as such by Gurovich and Cohen-Kastro (2004) based on voting patterns. The results of the simulation indicate slight reductions in income segregation levels. For example, the simulated DI of top and bottom deciles in 2008 is 0.38 , compared to 0.39 for the total sample of tracts. The simulation for 1995 reveals the same reduction of DI (0.01), 0.33 compared to 0.34 for the total sample. The indices computed for top and bottom quintiles and for the top and bottom 3 deciles show a consistent reduction of 0.01 for both 1995 and 2008. Altogether, the simulated DI show reductions ranging between 2 and $4 \%$ when excluding tracts which are predominantly Arab or ultra-orthodox, indicating a weak effect of the presence of those specific populations on income segregation in both years.

\subsection{Changing Spatial Distributions of Top and Bottom Income Quintiles in the Tel-Aviv MA}

The period 1995-2008 was not only dramatic in terms of the growth and expansion of the MA, but also in terms of change in the socio-spatial structure. The change is very much evident in maps that portray the spatial distributions of the top income quintile (Fig. 10.3, top panel). In 1995, census tracts that were characterized by the highest Location Quotient (LQ) of the top income quintile (i.e. those with the highest concentration of high-income residents) were scattered and quite uniformly spread throughout the MA. In 2008, such census tracts were substantially more clustered, and their spatial distribution was skewed to the north; most large clusters of neighbourhoods of the highest LQ can be found in the northern part of the MA, while in the south such neighbourhoods remained scattered. The visual impression of the differences between the maps, however, is distorted by the significant increase in the 
10 Increasing Inequality and the Changing Spatial Distribution of Income ...

LQ top quintile

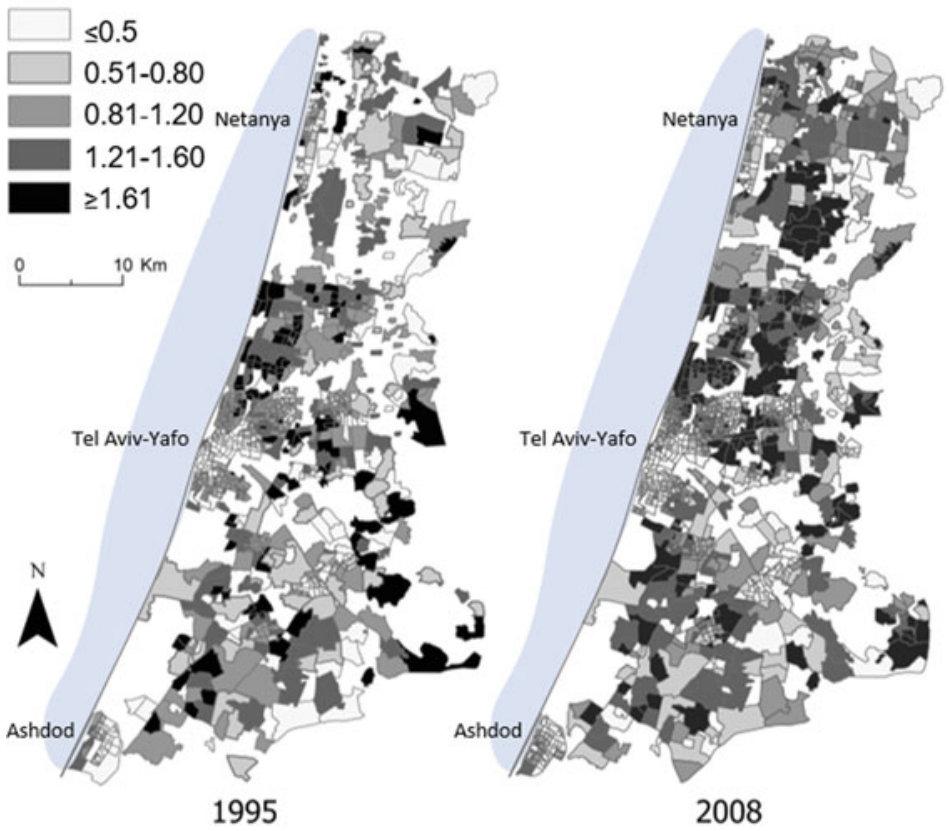

LQ_bottom quintile

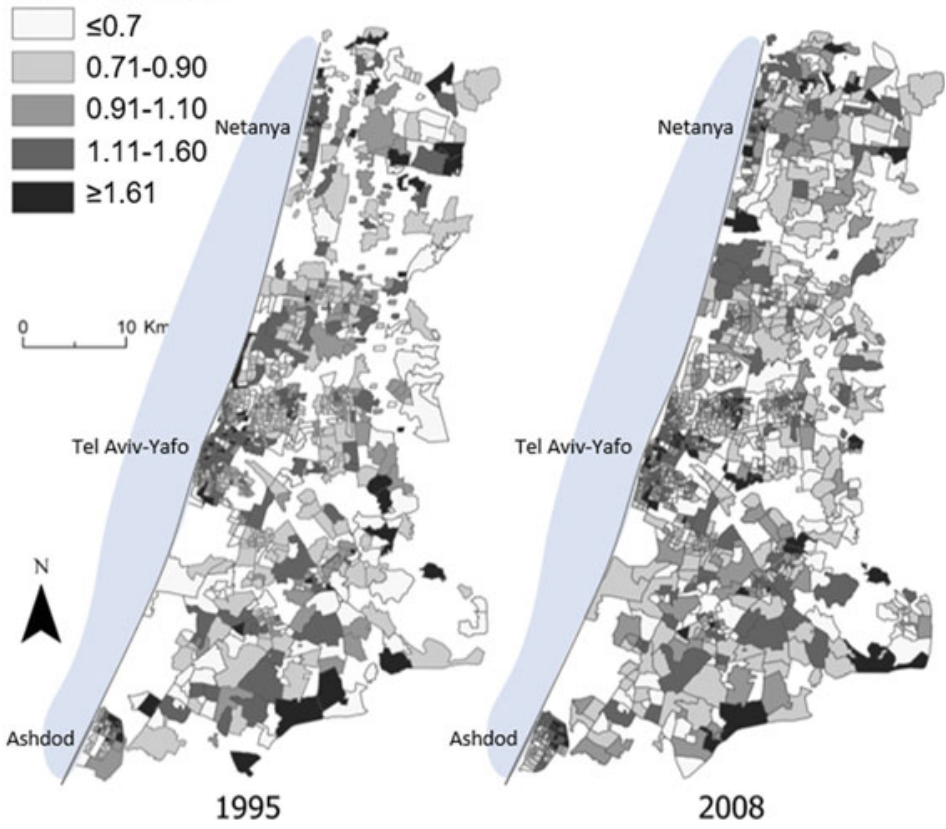

Fig. 10.3 Location quotients of the top and bottom income quintile (top and bottom panels, respectively) in the Tel-Aviv MA, 1995 and 2008 (Processed by author based on the census data acquired specifically for this research from the Israeli CBS) 
number of neighbourhoods during that period. Both the numbers of neighbourhoods characterized by the highest and lowest LQ increased. However, in percentage terms, the former increased from 12 to $17 \%$, whereas the latter stayed stable. Further examination reveals that neighbourhoods with very high concentrations of high-income residents increased at the expense of more mixed neighbourhoods with moderate concentrations, as will also be confirmed in subsequent analysis. As for the spatial distribution of the bottom income quintile, (Fig. 10.3, bottom panel), there is no substantial change over the study period in clustering patterns and locations of neighbourhoods with different relative shares of low-income residents. Moreover, the shares of each LQ categories were similar in 1995 and 2008.

\subsection{Changing Socioeconomic Compositions in Tel-Aviv Neighbourhoods}

The changing spatial distribution of income groups is also reflected in how they mix within neighbourhoods. Based on a typology of neighbourhood socioeconomic compositions from Marcinczak et al. (2015), which is based on occupational groups, in this chapter, the neighbourhoods are classified according to the composition of income classes. Each neighbourhood type is characterized by a distinctive mix of income classes which is defined by the shares of individuals pertaining to each class. Income classes to which individuals pertain were defined based on income deciles: Those pertaining to the three top and three bottom deciles were considered as pertaining to 'high' and 'low' income classes, respectively. Those pertaining to the four middle deciles (4-7) were considered as pertaining to the 'middle' income class.

During the study period, the share of neighbourhoods that were classified as 'mixed' decreased significantly (from 33.6 to 22.7\%). This decrease was accompanied by a substantial increase in the proportion of neighbourhoods with high and middle-high statuses (from 36.3 to $45.9 \%$ ) and a lesser increase in the proportion of middle-low neighbourhoods. Interestingly, the proportion of low-income neighbourhoods slightly decreased, but it was very small in the first place $(2.4 \%$ in 1995 and $1.6 \%$ in 2008).

The changing distribution of metropolitan neighbourhoods among types involved distinctive spatial patterns (Fig. 10.4). While the decrease in the proportion of mixed neighbourhoods seems to be uniformly spread, the increase in high and highmiddle neighbourhoods is not even. The emergence of high-income neighbourhoods was mainly in the north part of the MA, closer to the core. Middle-high-income neighbourhoods emerged in the southern part of the metropolitan area and in its northern outskirts. Middle-low-income neighbourhoods continued to cluster in the most urbanized areas (visually they can be identified as the smaller tracts). Polarized neighbourhoods changed locations completely between 1995 and 2008, implying that polarization characterizes neighbourhoods in transition. A close inspection reveals 

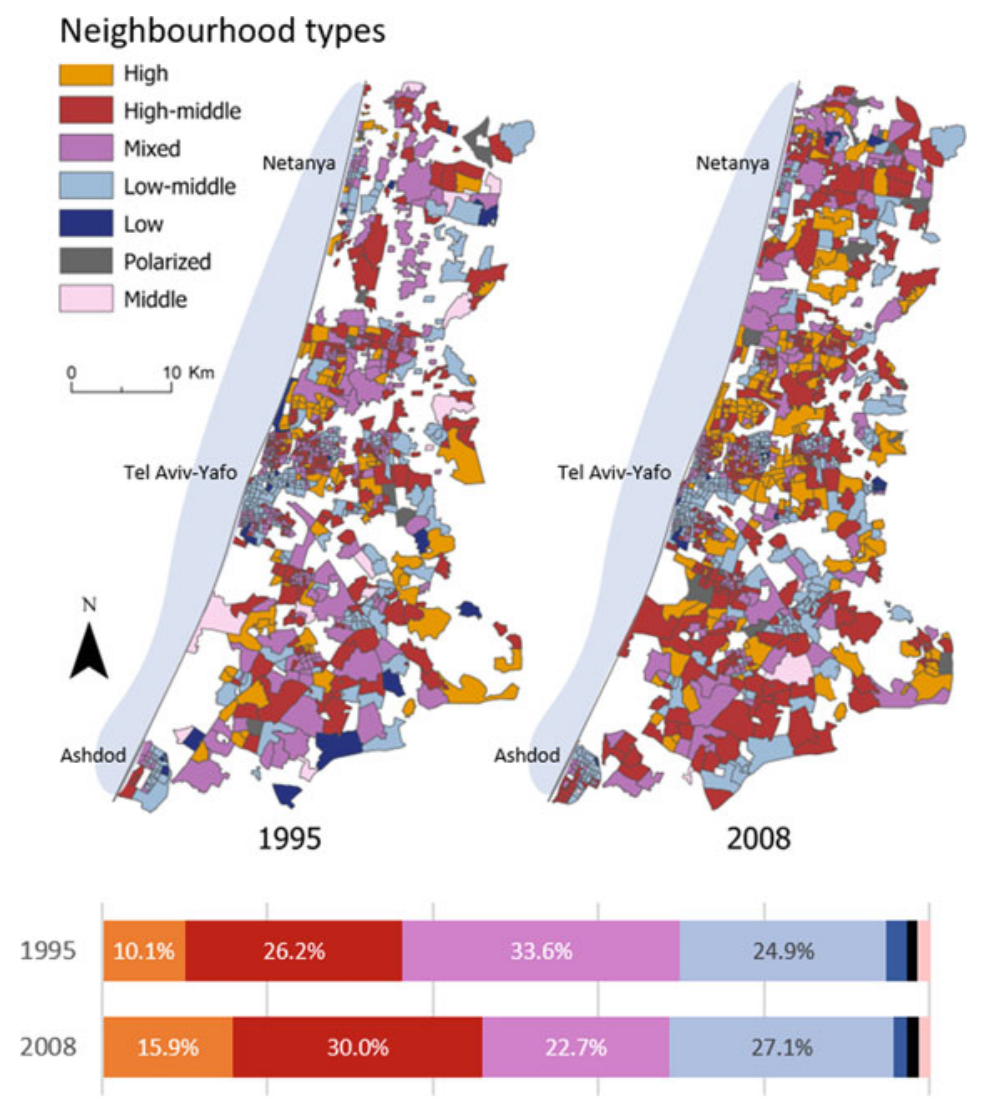

घhigh $\mathbf{m}$ Middle-high $\mathbf{m}$ Mixed $\mathbf{m}$ Middle-low $\mathbf{m}$ Low $\mathbf{a}$ Polarized $\mathbf{m}$ Middle

Fig. 10.4 The distribution (bottom panel) and spatial distribution (top panel) of neighbourhood types based on their income composition in the Tel-Aviv MA, 1995 and 2008 (Processed by author based on the census data acquired specifically for this research from the Israeli CBS)

that neighbourhoods that were polarized in 1995 were predominantly middle-highor high-income in 2008. Polarization can be thus considered a temporary phase that characterizes upgrading neighbourhoods. While in most urban areas, this process would be associated with gentrifying inner-city neighbourhoods, in the Tel-Aviv MA at that period this process is rather associated with the upgrading of rural places at the outskirts of the MA. Those places did not only experience generational replacement but also expansion and development following the massive conversion of agricultural land to residential use. 


\subsection{Conclusions}

This study explores the changing spatial distribution of incomes in the metropolitan area of Tel-Aviv, Israel. It is focused on the period between 1995 and 2008 during which inequality increased substantially. The study addresses a series of questions of which the first deals with the segregation of different classes and the connection to inequality trends. Predictions regarding this question were quite correct. Segregation of top and bottom income groups significantly increased between 1995 and 2008, for all group definitions (narrower and wider), as reflected in dissimilarity indices. The segregation of top and bottom quintiles was larger than the segregation of top and bottom deciles, which corresponds to the fact that Israel does not stand out in income shares held by the top decile or centile. The segregation of affluence was much higher than the segregation of poverty in both years, and its rate of increase was the highest. This corresponds to the trends in upper tail inequality. Trends in income segregation also correspond to the changes in the distribution of neighbourhoods among neighbourhood types according to their income composition. A decline of around $50 \%$ in the proportion of neighbourhoods which were 'mixed' is quite a dramatic change in the socio-spatial structure which inevitably means an increase in segregation.

The second question was whether the increasing relative disadvantage of Arabs and ultra-orthodox Jews played a role in increasing income segregation. The simulation of dissimilarity indices after excluding predominantly Arab and ultra-orthodox tracts revealed that the two distinct populations seem to not have a significant effect on income segregation in metropolitan Tel-Aviv; the exclusion of those tracts reduced between $2 \%$ and $4 \%$ of segregation measures. The effect of the presence of those disadvantaged groups on residential segregation is much weaker than we would expect, given the substantially higher poverty rates among those groups and the significant increase in poverty rates during the period 1992-2011 (Ben-David and Bleikh 2013). This may be related to the under-representation of the groups in the TelAviv MA (especially the Arab group which makes up around 5\% of the metropolitan population compared to $20 \%$ in the total Israeli population). Another possible explanation is that disparities between those groups and the majority population within the MA are lesser than at the national level. This possibility should be addressed in further research provided that sufficient individual-level data of these groups can be collected, which is especially challenging in the case of ultra-orthodox Jews.

The last question deals with how income classes were spatially distributed across the MA over time, and whether there are indications of changing spatial patterns of affluence/poverty concentration. The maps provide preliminary indications regarding the changing socio-spatial structure of the MA and the changing concentration of affluence and poverty over the research period. Location quotient maps show that lowincome classes were quite evenly spread both in 1995 and 2008, whereas high-income classes became very spatially clustered in 2008. The clusters of affluent groups are much larger in 2008 than in 1995 and indicate that they no longer concentrate in specific neighbourhoods but in entire districts or cities. This change may have a 
negative impact on the potential interaction among classes and on the distribution of economic and political resources featured at the municipality level.

The numbers of high- and middle-high-income neighbourhoods increased significantly over time and so did their shares of total metropolitan neighbourhoods. The changing distribution of neighbourhoods among types involved particular spatial patterns. The map of neighbourhood types highlights a distinction between the spatial distributions of high- and middle-high-income neighbourhoods. In 1995, both were evenly spread across the MA, apart from a slight under-representation of high-income neighbourhoods in the far north of the metropolitan area. In 2008, high-income neighbourhoods were clustered across the entire northern part of the metropolitan area, and especially close to the core; middle-high-income neighbourhoods emerged in the southern part of the metropolitan area and in the northern outskirts. This finding adds insight into the patterns of north-south polarization.

Poverty rates in Israel are among the highest in the OECD, but both the location quotient map and the neighbourhood types map indicate that there was hardly any concentration of poverty in the MA in either year. There were very few scattered poor neighbourhoods. The lowest prevalent neighbourhood status was low-middle-income neighbourhoods. In that respect, it can be said that the socioeconomic landscape of the Tel-Aviv MA, despite the high inequality and poverty rates in Israel, is different than urban areas in the United States where concentrated poverty is an issue of great concern. There is, however, some difference between the classification of 'concentrated poverty' in the United States and 'low-income' neighbourhoods in the context of this study, which should be considered. Neighbourhoods of concentrated poverty in the United States are usually characterized as those with at least $40 \%$ poor (e.g. Jargowsky 2013). In this study, low-income neighbourhoods are those in which at least $50 \%$ of the residents are low income. However, low-income residents in this classification are those pertaining to the three bottom deciles, which is a much wider group than those defined as strictly poor. With poverty rates in Israel of around $18 \%$, the poor can be defined approximately as those pertaining to the two bottom deciles. The inclusion of low-income people who are not considered strictly 'poor' should compensate for the reductionist $50 \%$ definition of neighbourhoods with concentrated poverty.

Altogether, this study reveals trends of increasing income segregation in Tel-Aviv MA, which conforms to other cities in the developed world. However, the finegrained picture of segregation reflects particular inequality trends in Israel, as well as the interaction with its particular socioeconomic landscape and patterns of urban development.

\section{References}

Ben-David D, Bleikh H (2013) Poverty and inequality over time in israel and in the OECD. In: State of the nation report: society, economy and policy in Israel 2013. Taub Centre for Social Policy Studies in Israel. 
Bittner C, Sofer M (2013) Land use changes in the rural-urban fringe: an Israeli case study. Land Use Policy 33:11-19. https://doi.org/10.1016/j.landusepol.2012.11.013

Carmon N (2001) Housing policy in Israel: review, evaluation and lessons. Isr Aff 7:181-2008. https://doi.org/10.1080/13537120108719620

Central Bureau of Statistics (Israel), Population censuses. https://www.cbs.gov.il/en/Surveys/Pages/ Population-Census.aspx

Cornfeld O, Danieli O (2015) The origins of income inequlaity in Israel—trends and policy. Isr Econ Rev 12:51-95

Falah G (1996) Living together apart: residential segregation in mixed Arab-Jewish Cities in Israel. Urban Stud 33:823-857

Friedman I, Shaul-Mena N, Fogel N et al (2011) Measurement and estimates of the population of ultra-orthodox Jews

Gurovich N, Cohen-Kastro E (2004) Ultra-orthodox Jews-geographic distribution and demographic, social and economic characteristics of the ultra-orthodox jewish population in Israel 1996-2001

Haberfeld Y, Cohen Y (2007) Gender, ethnic, and national earnings gaps in Israel: the role of rising inequality. Soc Sci Res 36:654-672. https://doi.org/10.1016/J.SSRESEARCH.2006.02.001

Hananel R, Perlman S, Vatury A, Krefetz SP (2018) Housing matters: public housing policy in Sweden, the United States, and Israel. J Plan Educ Res. https://doi.org/10.1177/0739456X1879 3702

Jargowsky PA (2013) Concentration of poverty in the new millennium: changes in prevalence, composition, and location of high poverty neighborhoods. Century Foundation and Rutgers Center for Urban Research and Education.

Kipnis BA (2004) Tel Aviv, Israel—a world city in evolution: urban development at a deadend of the global economy. Dela 21:183-193

Kraus V, Koresh Y (2012) The course of residential segregation: ethnicity, socioeconomic status, and suburbanization in Israel. Sociol Q 33:303-319

Marcińczak S, Musterd S, van Ham M, Tammaru T (2015) Inequality and rising levels of socioeconomic segregation: lessons from a pan-E. In: Tammaru T, van Ham M, Marcińczak S, Musterd $\mathrm{S}$ (eds) Socio-economic segregation in european capital cities: east meets west. Routledge, London

Marcinczak S, Tammaru T, Novák J et al (2015) Patterns of socioeconomic segregation in the capital cities of fast-track reforming postsocialist countries. Ann Assoc Am Geogr. https://doi.org/10. 1080/00045608.2014.968977

Modai-Snir T, van Ham M (2018) Neighbourhood change and spatial polarization: the roles of increasing inequality and divergent urban development. Cities 82:108-118. https://doi.org/10. 1016/J.CITIES.2018.05.009

OECD (2015) In it together: why less inequality benefits all. OECD Publishing, Paris. https://doi. org/10.1787/9789264235120-en

Quillian L, Lagrange H (2016) Socioeconomic segregation in large cities in France and the United States. Demography 53:1051-1084. https://doi.org/10.1007/s13524-016-0491-9

Razin E (1996) Trends in the urban-rural fringe of the Tel-Aviv metropolis and their implications for the organization of local government. Floresheimer Inst Policy Stud, Jerusalem

Reardon SF, Bischoff K (2011) Income inequality and income segregation. Am J Sociol 116:10921153. https://doi.org/10.1086/657114

Shilhav Y (1993) The emergence of ultra-orthodox neighbourhoods in Israeli urban centres. In: Ben E (ed) Local communities and the Israeli polity: conflict of values and interests. State University of New-York Press, Albany, NY, pp 157-187

Tammaru T, Marcinczak S, Aunap R et al (2019) Relationship between income inequality and residential segregation of socioeconomic groups. Reg Stud 1-12. https://doi.org/10.1080/003 43404.2018.1540035

Tammaru T, Marcińczak S, Van Ham M, Musterd S (2015) Socio-economic segregation in European capital cities: east meets west. Routledge, London 
Watson T (2009) Inequality and the measurement of residential segregation by income in American neighbourhoods. Rev Income Wealth 55:820-844. https://doi.org/10.1111/j.1475-4991.2009.003 46.x

Werczberger E (1995) The role of public housing in Israel: Effects of privatization. Scand Hous Plan Res 12:93-108. https://doi.org/10.1080/02815739508730378

Werczberger E, Reshef N (1993) Privatisation of public housing in Israel: inconsistency or complementarity? Hous Stud 8:195-206. https://doi.org/10.1080/02673039308720761

Open Access This chapter is licensed under the terms of the Creative Commons Attribution 4.0 International License (http://creativecommons.org/licenses/by/4.0/), which permits use, sharing, adaptation, distribution and reproduction in any medium or format, as long as you give appropriate credit to the original author(s) and the source, provide a link to the Creative Commons license and indicate if changes were made.

The images or other third party material in this chapter are included in the chapter's Creative Commons license, unless indicated otherwise in a credit line to the material. If material is not included in the chapter's Creative Commons license and your intended use is not permitted by statutory regulation or exceeds the permitted use, you will need to obtain permission directly from the copyright holder. 